\title{
TITLE
}

\section{Triadic awareness predicts partner choice in male-infant-male interactions in Barbary macaques}

\author{
Barbora Kuběnová a,b, Martina Konečnáa ${ }^{a}$, Bonaventura Majolo ${ }^{c}$, Petr Šmilauer ${ }^{d}$, Julia \\ Ostner $^{\text {be }}$, Oliver Schülke ${ }^{\text {be }}$
}

\section{a Department of Zoology, Faculty of Science, University of South Bohemia, České} Budějovice, Czech Republic, b Department of Behavioral Ecology, Johann-Friedrich-Blumenbach Institute for Zoology and Anthropology, Georg August University Göttingen, Germany c School of Psychology, University of Lincoln, U.K.

d Department of Ecosystem Biology, Faculty of Science, University of South Bohemia, České Budějovice, Czech Republic

e Research Group Primate Social Evolution, German Primate Centre, Göttingen, Germany

\begin{abstract}
Social knowledge beyond one's direct relationships is a key to successful maneuvering of the social world. Individuals gather information on the quality of social relationships between their group companions, which has been termed triadic awareness. Evidence of the use of triadic awareness in natural contexts is limited mainly to conflict management. Here we investigated triadic awareness in wild Barbary macaques (Macaca sylvanus) in the context of bridging interactions defined as male-infant-male interactions whereby a male (actor) presents an infant to another male (receiver) in order to initiate an affiliative interaction with that male. Analyses based on 1,263 hours of focal observations on ten infants of one wild social group in Morocco supported the hypothesis that males use their knowledge of the relationship between infants and other adult males when choosing a male as a partner for bridging interactions.

Specifically, (i) the number of bridging interactions among initiator-infant-receiver triads was affected by the strength of the infant-receiver relationship and (ii) when two males were available as bridging partners, a male was more likely to be chosen as the receiver the stronger his social relationship with the infant in comparison to the other available male was. This demonstrates that non-human primates establish triadic awareness also of temporarily rather dynamic infant-male relationships and use it in naturally occurring affiliative context. Our results contribute to the discussion about the mechanism underlying the acquisition of triadic awareness and the benefits of its usage and lend support to hypotheses linking social complexity to the evolution of complex cognition.
\end{abstract}

\section{KEYWORDS}

Triadic awareness, social cognition, infant-male affiliative relationships, infant handling, bridging, male-infant-male interactions, Barbary macaques 


\section{INTRODUCTION}

Nonhuman primates living in stable social groups develop agonistic and affiliative relationships with group members of the same and other age-sex classes (e.g. Cheney et al. 1986; van Hooff and van Schaik 1994; Silk et al. 2006). Social relationships are defined as being established by social partners who individually recognize each other, repeatedly interact with one another over time and where past interactions among the two are predictive of future ones (Hinde 1976). This definition suggests that individuals possess knowledge about their own relationships that they use to modify their own behaviour towards others and that may also allow them to predict the behaviour of others. This capacity helps the individual to avoid aggression (e.g. De Waal 1986; van Hooff and van Schaik 1994), to increase fitness (Silk et al. 2003; Silk 2007a, b; Silk et al. 2009; Schülke et al. 2010) and contributes to the stability and cohesion of the group (e.g. Sterck et al. 1997; Lehmann et al. 2007). It has been suggested that the challenges of social life might drive the evolution of complex social knowledge, so-called triadic awareness, that is, knowledge about the relationships among other individuals. The capacity to recognize who outranks whom, who is closely bonded with whom, who is likely to support whom or intervene against whom, and to adjust one's behaviour accordingly has been documented in apes (e.g. Tomasello and Call 1997; De Waal 2007), Old World (Cheney et al. 1986; Cheney and Seyfarth 1999), New World monkeys (Perry et al. 2004; but see also Ferreira et al. 2006), other mammals (Engh et al. 2005; Connor 2007; Johnson 2010) and in birds (Peake et al. 2002; Seed et al. 2007).

Evidence for triadic awareness of non-human primates mainly comes from experiments. Male hamadryas baboons (Papio hamadryas) used knowledge of the quality of male-female relationships when deciding whether to challenge a given male for access to females (Bachmann and Kummer 1980). Adult vervet monkeys, Cercopithecus aethiops, react to play-backs of juvenile distress vocalizations by looking at the juvenile's mother indicating triadic awareness of kin relations (Cheney and Seyfarth 1980). Triadic awareness of rank relationships has been inferred from playback experiments using artificial sequences of calls of group members: calls mimicking interactions that were discordant with the current dominance relations between parties elicited stronger reactions in group members than calls in accordance with the hierarchy (Cheney et al. 1995; Kitchen et al. 2005).

Another set of studies used observational data on social behaviour in natural contexts to assess triadic awareness of others' dominance, kin and affiliative relationships. Individuals engaging in agonistic conflicts solicit support and target solicitations more often from group mates who outranked their opponent (e.g. Silk 1999) and from individuals with whom they were more closely bonded than their opponents (Perry et al. 2004). Support is likely to be offered to the higher ranking of the opponents (Schino et al. 2007). After the conflict, individuals may discriminate the opponent's kin or affiliates. The aggressor directs reconciliatory behaviour at the opponent's close relatives (Judge 1991) or avoids affiliative interactions with them in expectation of retaliation (Call et al. 2002). The victim redirects aggression to the opponent's kin (Judge 1982; Smuts 1985; Cheney and Seyfarth 1989).

Although these patterns imply the usage of triadic awareness, it has been pointed out that some patterns may be also result of alternative, simpler mechanisms, such as recruitment of allies based on own affiliative or dominance relationship or simple rule of the recruitment of the highest available individual (Silk 1999; Perry et al. 2004; Range and Noë 2005; Schino et al. 2006). This ambiguity may partly arise from the relative rarity of the interactions suitable for the research question: supporter recruitment only demonstrates the use of triadic awareness if the invitee recruits the higher ranking from both opponents and is not ranking in 
between them at the same time. Elegant experiments have been designed to rule out such alternative mechanisms and may more effectively demonstrate the cognitive capacity for triadic awareness (De Waal 1991; Schino et al. 2006; Schino et al. 2007). Nevertheless, these experiments are less informative about the use of this cognitive capacity and its biological relevance. Studying triadic awareness under natural conditions therefore should complement experimental research (De Waal 1991). New observational studies should focus on underexplored social contexts that provide a more complete understanding of whether and how individuals use triadic awareness in different situations of their daily lives Here we focus on a frequently occurring behaviour that may allow assessing how triadic awareness is used in a natural affiliative context, specifically a type of polyadic infant handling so called bridging interactions (Ogawa 1995a) in male Barbary macaques.

Infant handling is broadly defined as non-maternal manipulation of an infant by individuals other than the infant's mother and may include different positive, neutral and also negative interactions between the infant and its non-maternal caretaker irrespective of the caretakers' sex and age class (Hrdy 1976; Paul et al. 2000; Hrdy 2007). Infant handling is found across different taxa (see Riedman 1982 for a review; Clutton-Brock 2006) with pronounced interspecific variation in intensity and type of interactions (Whitten 1987; Woodroffe and Vincent 1994; Hrdy 2007). In several species of Old World monkeys, males engage in a specific type of polyadic infant handling so called bridging interactions (Ogawa 1995a), triadic male-infant interactions (Taub 1980), male-infant-male interactions (Zhao 1996), or agonistic buffering (Deag and Crook 1971). During these interactions typically two males simultaneously manipulate one infant exhibiting a typical series of ritualized behaviour including teeth chattering, lifting the infant above their heads and inspection of the infant's genitals (see Deag 1980). Bridging has been reported in several papionin primates: Barbary Macaca sylvanus (Deag and Crook 1971), Tibetan M. thibetana (Ogawa 1995a), stumptail M. acrtoides (Estrada and Sandoval 1977), longtail M. fascicularis (de Waal et al. 1976), Assamese M. assamensis (Bernstein and Cooper 1998) and bonnet macaques M. radiata (Silk and Samuels 1984) as well as yellow Papio cynocephalus (Collins 1986), olive P. anubis (Smuts 1985) and chacma baboons P. ursinus (Busse and Hamilton 1981), sooty mangabeys Cercocebus atys (Busse and Gordon 1984), gray-cheeked mangabeys Cercocebus albigena (Chalmers 1968) and geladas Theropithecus gelada (Dunbar 1984).

Dyadic infant handling and bridging interactions are often non-equally distributed among infants and potential handlers. Males differ in their general interest in infant handling and also in preferences for particular infants (e.g. Taub 1980). In some baboon species, these preferences may reflect likelihood of paternity to some extent (Nguyen et al. 2009; Moscovice et al. 2010). In macaques male preferences for infants appear mostly unrelated either to paternity or to past mating (Paul et al. 1992; Ménard et al. 2001; but see Ménard et al. 1992 and Ostner et al. 2013) but may reflect the male's social relationships with the mother and may be predictive of future mating opportunities (Ménard et al. 2001; see also Smuts and Gubernick 2015). Males also choose the male partner in the bridging interaction nonrandomly (e.g. Estrada and Sandoval 1977; Dunbar 1984; Taub 1984; Ogawa 1995a). Males initiate bridging interactions more often with relatively higher ranking males than with lower ranking (Paul et al., 1996; Silk and Samuels 1984; Collins 1986; Deag 1980) and/or with males, who are relatively close to their own rank (Stein 1984; Paul et al. 1996). It has been suggested also that the male initiating the bridging interaction preferentially uses the infant that is preferred by the receiver to increase the chances of a successful interaction, indicating that males recognize affiliative relationships between other males and infants (Ogawa 1995b). This suggestion implies the use of triadic awareness in bridging interactions. Patterns of interactions in accordance with this mechanism have been found in Barbary macaques (Paul 
et al. 1996), but the element of choice has not yet been systematically studied.

Barbary macaques live in multimale-multifemale groups. Males emigrate from their natal group after reaching sexual maturity, while females remain in the natal group with their offspring. They are seasonal breeders with a mating season in autumn and a birth season in spring (reviewed in Fooden 2007). Females mate with numerous males (Small 1990) and paternal kinship is not recognized (Ménard et al. 2001; Kuester et al. 1994; but see also Ménard et al. 1992). Despite of the promiscuity selecting against male care for offspring (see van Schaik and Paul 1996), infants may spend exceedingly large proportions of the time being carried, cradled and groomed by males, whereas aggression or abuse by males are rare (e.g. Deag 1980; Whitten 1987; Paul 1999). Most interactions are initiated and maintained by males, but the contact seems voluntary and infants can be responsible for its start or termination (BK personal observation). Male infant handling bouts can take up to 20 minutes (Deag and Crook 1971) and up to over an hour (BK personal observation) and are often alternated with bridging interactions.

In this study we investigated the interrelation between the strength of the infantmale affiliative relationship and the distribution of bridging interactions initiated by the adult male holding the infant. We expected that the stronger the relationship between the infant and another male the higher would be his chance of being picked as partner for a bridging interaction by the infant holder. This implies triadic awareness on the part of the infant holder who initiates the interaction (Ogawa 1995b). Unlike previous study (Ogawa 1995b) we assumed that an infant holder chooses a receiving male based on the infant he has instead of searching for an infant that fits his pre-selected male partner (receiver). This assumption is more plausible for Barbary macaques, because bridging interactions are often preceded by extended dyadic infant carrying and handling episodes. More specifically, we predicted that the number of interactions of each initiator-infant-receiver triad would be predicted by the strength of the affiliative relationship between the infant and the receiver of the interaction. We also predicted that the stronger a male's relationship with the infant relative to a second available male (the closest bystander) is, the more likely he is chosen as the receiver of the interaction.

\section{METHODS}

\section{Field site and subjects}

This study was conducted on one group of Barbary macaques inhabiting the cedar and oak forest of the Ifrane National Park in the Middle Atlas Mountains of Morocco $\left(33-240^{\circ} \mathrm{N}\right.$, $\left.005-120^{\circ} \mathrm{W}\right)$. Permission to conduct the research in the park was granted by the Haut Commissariat aux Eaux et Forêts et à la Lutte Contre la Désertification of Morocco.

The data were collected by BK during two field seasons corresponding with two following birth seasons (April-August 2013, April-September 2014). The study group (Green Group) was well habituated to the presence of human observer and all members were individually recognizable. In both seasons, the group consisted of 7 adult males and 6 adult females. There were 19 juveniles in 2013 and 20 in 2014. All adult females gave birth in both seasons resulting in 6 infants in each season ( 5 female, 1 male in 2013; 3 female, 3 male in 2014).

\section{Data collection}


Behavioural data were collected using handheld HP iPAQ 114 series pocket PCs loaded with Pendragon Forms Version 5.1 () Pendragon Software Cooperation, U.S.A.). We used continuous focal sampling (Altmann 1974) with infants as focal subjects. In both seasons, the data collection started when at least 4 infants were born. We observed all infants until the end of the field season, except of one male infant (born in 2014), who disappeared about two months after his birth. Infants were followed during two hour observation sessions, during which we recorded all social interactions between the focal infant and other group members. We pseudorandomized the order in which we observed infants to ensure that all infants were observed equally often at the different times of the day. The data collection on the 12 infants yielded a total of 1,430 hours of observation. We excluded two infants that never interacted with adult males from the analyses. Thus the analyses were based on 1,263 hours of focal observation of 10 infants (mean hours of focal data per infant \pm SD $=126.3 \pm$ 12.5)

We defined dyadic infant handling as an interaction between an adult male and an infant. During the interaction the adult male and infant were in body contact that included cradling, dorsal carrying, ventral carrying, grooming, resting in body contact and "contact crawling" defined as an infant crawling in body contact with a male or playfully climbing over a male's body (see Thierry et al. 2000; Deag 1980) for more detailed description of the behaviors). We also included polyadic interactions if they involved only one adult male and one or more females or non-adult males (e.g. a male manipulates an infant together with a juvenile individual or the mother of the infant). For each dyadic infant handling interaction, we recorded the start, end and ID of the male involved.

We defined bridging as an interaction involving (at least) two adult males, who simultaneously manipulated one infant exhibiting a series of ritualized behavior including teeth-chattering or lip smacking, inspection of the infant's genitalia, lifting infant above heads (Deag 1980). We scored the start of the interaction once both males (being already in body contact with the infant and to each other) displayed teeth chattering in a way typical for bridging behavior. We classified the male approaching the other to start the body contact as the initiator and the male that was being approached as a receiver. For the interactions when males approached at the same time, the initiator was classified as unknown. The male who was in body contact with the infant before the bridging interaction started was labelled the infant holder. We scored the end of interaction once the males stopped being in mutual body contact with one another. A new independent bridging interaction was scored after a $>2 \mathrm{~min}$ break in body contact between males.

We sorted bridging interactions into three types (see also Paul et al., 1996; Zhao 1996; Ogawa 1995a): 1) interactions initiated by a male that is in dyadic interaction with the infant (initiator $=$ holder) and approached a male without an infant (receiver $=$ non-holder), 2) interactions initiated by the male without an infant (initiator $=$ non-holder), who approached a male that was already interacting with the infant (receiver $=$ holder), 3) other cases, i.e. interactions with unknown initiator, interactions initiated by both males, interactions, that were not preceded by dyadic handling between any of males participating on the bridging interactions. Only interactions belonging to the first category (bridging initiated by the infantholder) were considered suitable for the analysis of triadic awareness in this study because for the other two options we could not discriminate the target of the interaction (infant or adult male) or the role of the initiator. In the second field season, we expanded the data collection to obtain additional information about the choice of male partner and recorded also the ID of the nearest male present within 10 meters at the beginning of a bridging interaction and labeled him as a bystander. 
We used an ad libitum method (Altmann 1974) to record all dyadic agonistic interactions. For each season separately we entered the recorded data into a winner-loser dominance matrix and built a hierarchy based on the standardized normalized David's score (Schmid and De Vries 2013).

\section{Data analysis}

We used a composite sociality index (CSI; Silk et al. 2006) to assess the strength of dyadic affiliative relationships between infants and males. The CSI was based on: (1) the duration and (2) frequency of body contact (including ventral carrying, cradling, grooming and also infant directed polyadic behavior that involved one male and female or juvenile individual/s) and (3) the duration of crawling body contact as defined above. The three behaviors were highly correlated in row-wise matric correlations ( $\mathrm{rho}_{\mathrm{rw}, \mathrm{av}}$ ranged from 0.80 to 0.88) run with MatMan 1.1.4 (De Vries et al. 1993). For each dyad, we divided the value for each behavior by the average across all dyads this infant formed with all males in the group and overagedthe resulting relative value of all three behaviors. Thus the index expresses the relative strength of the bond of the infant-male dyad compared to bonds this infant had with all males. Any infant-male interaction was excluded, if being a part of bridging according to the definition, so that these two variables were independent from one another.

To test the predictions of our hypothesis, that holders choose receivers based on the strength of the relationship the receiver has with the infant we used two generalized linear mixed-effect models (GLMM) using the lme4 package (Bates et al. 2015) in R 3.1.1 (R Core Team 2014). Fitted models were assessed for over-dispersion and model stability (see Quinn and Keough 2002). We followed a stepwise model selection procedure based on the Bayesian information criterion (BICs) (Schwarz et al. 1978). Beyond the decisive choice of predictors using BIC, we also performed parametric tests for both the independent (compared against null model) and partial effects of each predictor. Collinearity of the selected predictors was assessed by variance inflation factor (Bowerman and O'Connell 1990). In the best models VIFs did not exceed 1.22.

To test prediction 1, whether the number of interactions of each initiator-infantreceiver triad is predicted by the strength of the bond between the infant and receiver, we used a GLMM with assumed Poisson distribution and the number of bridging interactions among each holder-infant-receiver triad as a response variable $(\mathrm{N}=654)$. We included the identities of the infant, holder and receiver as random factors to avoid pseudo-replication and a factor distinguishing each unique holder-infant-receiver triad to account for over-dispersion. The logarithm of the total observation time of each infant was entered as an offset. We considered following predictors as fixed effects: birth season, the David's score of the receiver (DSr), the rank distance between holder and receiver computed as an absolute value of the rank difference between holder and receiver $(|\Delta \mathrm{DSh}|)$, the CSI between holder and infant (CSIh) and the CSI between infant and receiver (CSIr).

To test prediction 2, whether the holder bases the choice of the receiver between two available males on their CSI with the infant we used a GLMM with assumed binomial distribution. The binomial response was scored as one if the male was selected to be the receiver and zero if the male remained a bystander to the bridging interaction $(\mathrm{N}=224)$. We entered the identities of the infant, the holder, the receiver and the bystander as random factors and following variables as predictors with a fixed effect: the rank distance between the holder and the involved male (receiver or bystander) calculated as absolute difference of their David's score $(|\Delta \mathrm{DShm}|)$, the rank distance between receiver and bystander calculated as difference between their David's score ( $\Delta \mathrm{DS} r b)$, and the difference between the CSI of the 
infant-receiver and the infant-bystander dyad (with positive values indicating the selection of the male with the stronger relationship with the infant and negative values indicating the selection of the male with the weaker relationship with the infant than the second male had) $(\Delta \mathrm{CSIrb})$.

\section{RESULTS}

\section{Distribution of interactions}

In 2013 we assessed the rank of males based on 124 interactions. The David's score ranged from -14.5 to 11.8 (median $=0.8)$ with $3(14.3 \%)$ dyads with unknown and $1(4.8 \%)$ with a two-way relationship. In 2014 the DS was based on 114 interactions and showed the same range as in the previous season (median $=0.7)$ with $2(9.5 \%)$ dyads with unknown and 4 (19\%) dyads with two-way relationships. The change of DS between seasons (in absolute values) ranged between 0 and 9.4 (median $=5.4$ ) for each male. All males engaged in dyadic infant handling and bridging interactions. The ten infants that were included into the analysis spent between $3.7 \%$ and $26.3 \%$ of focal observation time in dyadic infant handling interactions with males (mean $\pm \mathrm{sd}=16.2 \pm 7.2$ ). The durations of dyadic infant-handling interactions (continuous body contact uninterrupted by bridging interaction) varied between 2 seconds and 84.5 minutes (mean $\pm \mathrm{sd}=2.7 \pm 5.2$ ). The values of infant-male CSI based on these dyadic interactions ranged between 0 and 5.8 (median= 0.4 ) (Fig S1 of the supplement).

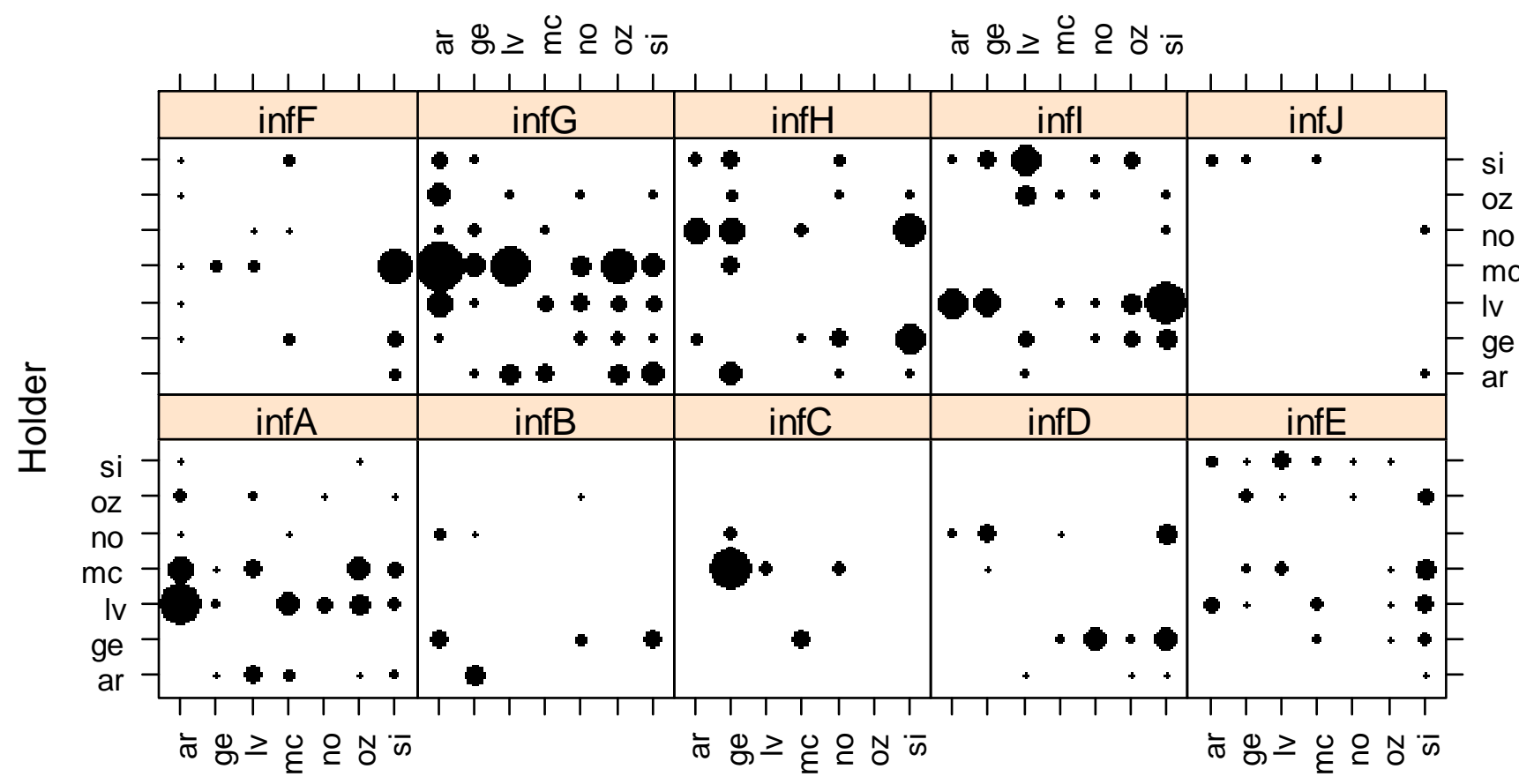

Receiver 
Fig 1:

Distribution of bridging interactions each infant (in separated panels) experienced with different holder-receiver dyads. The size of each point corresponds to the squared rate of bridging interactions among each triad (adjusted by the time of observation for each infant).

The dataset included 1,873 male bridging interactions (between 10 and 368 for each infant, mean $\pm \mathrm{sd}=187.3 \pm 122.1$ ) Of these 654 were initiated by a male holding the infant and were used for testing the first prediction (between 6 and 148 for each infant, mean $\pm \mathrm{sd}=$ $65.4 \pm 46.2$ ). These interactions were distributed among 155 initiator-infant-receiver triads (from 420 possible). The distribution of interactions is shown in Fig 1 and Table S1 of the attached supplement. We recorded the ID of the bystander for 209 of these interactions. A bystander was present in 112 cases (between 4 and 38 cases for each of 6 infants followed during the second season) which we used for testing prediction 2 . The dataset included interactions with all males participating as holders (range $=5$ to 36), receivers (range $=9$ to 36) and bystanders (range $=12$ to 18 ). For more details about the distribution of interactions, see Fig 2 and Table $\mathrm{S} 2$ of the supplement. 


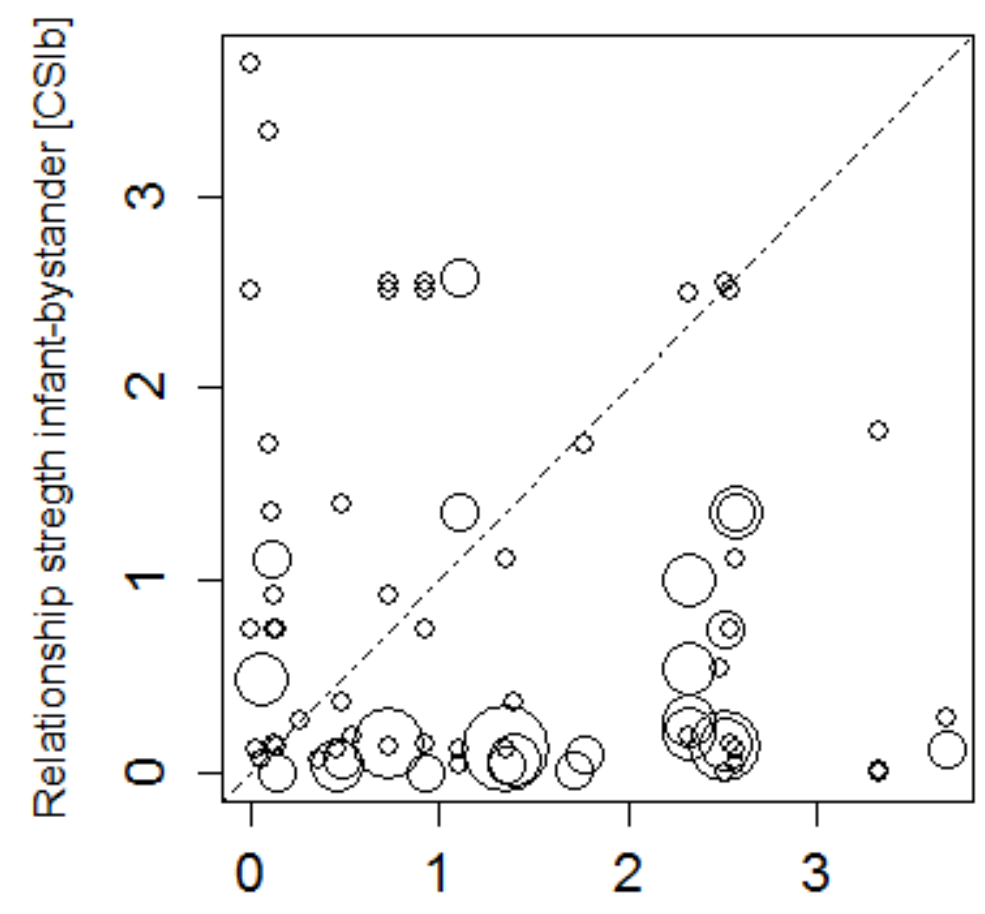

\section{Relationship stregth infant-receiver [CSIr]}

Fig 2: Relationship between the strength of the social relationship (measured as composite sociality index, CSI) between the infant and the receiver (CSIr) and between the infant and the bystander (CSIb). Data points below the diagonal indicate that the receiver had a higher CSI with the infant than the bystander. The size of data points indicates the number of interactions among same infantreceiver-bystander triad. In $72 \%$ of cases the holder chose the male with the stronger bond to the infant as a partner for a bridging interaction.

The model selection results for the model testing prediction 1 are summarized in table S2 of the supplement. The CSI between infant and holder (CSIh) and between infant and the receiver (CSIr) both increased the model's quality. Season, rank of the receiver (DSr) and the difference between rank of the holder and receiver $(|\Delta \mathrm{DShr}|$ did not improve either the null model or the models with CSIh and/or CSIr. We thus fitted our final model only with CSIh and CSIr as predictor variables. The frequency of bridging interactions among the holderinfant-receiver triad was significantly increasing with increasing CSIh and increasing CSIr (ranging between 0 and 5.8), see Table 1, Fig 3. The model predicted that an increase of CSIh by 1.0 increased the expected frequency of interaction 2.3-3.1 times, and each increase of CSIr by 1.0 increased the expected frequency of interactions 1.7- 2.2 times (95\% CI). There was no substantial collinearity between the two predictors (VIF=1.21).

Table 1: Result of the final model for GLMM predicting the frequency of bridging interactions between two males and a specific infant with social relationship strength between infant and holder (CSIh) and social relationship strength between infant and receiver (CSIr) as predictors. 


\begin{tabular}{lllll}
$\mathrm{N}=654$ & Estimate & $\mathrm{SE}$ & \multicolumn{2}{c}{$95 \%$ confidence interval } \\
\hline Intercept & -4.550 & 0.526 & -5.679 & -3.50 \\
CSIh & 0.677 & 0.072 & $\mathbf{0 . 8 3 1}$ & $\mathbf{1 . 1 2 2}$ \\
CSIr & 0.972 & 0.074 & $\mathbf{0 . 5 3 7}$ & $\mathbf{0 . 8 2 0}$
\end{tabular}

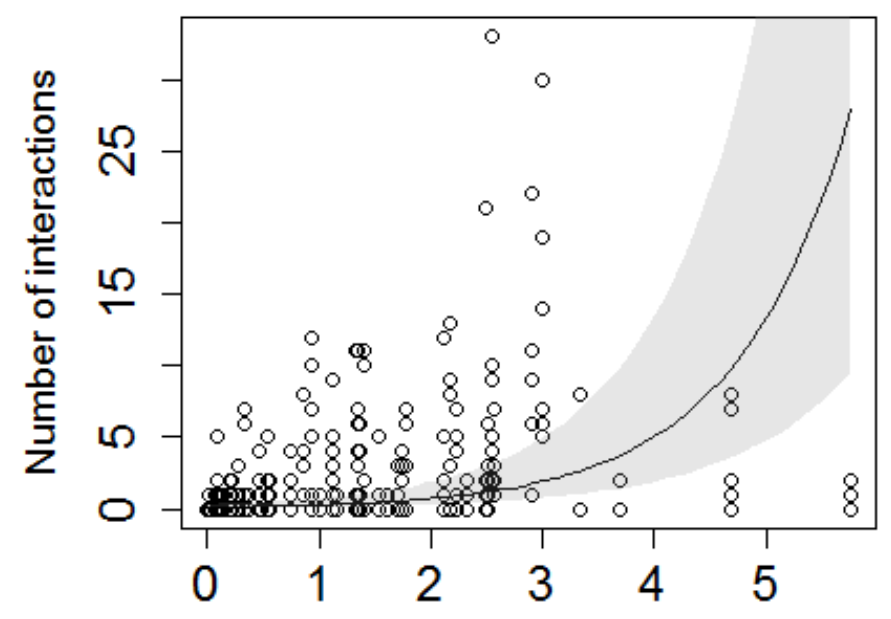

Relationship strength infant-holder [CSIh]

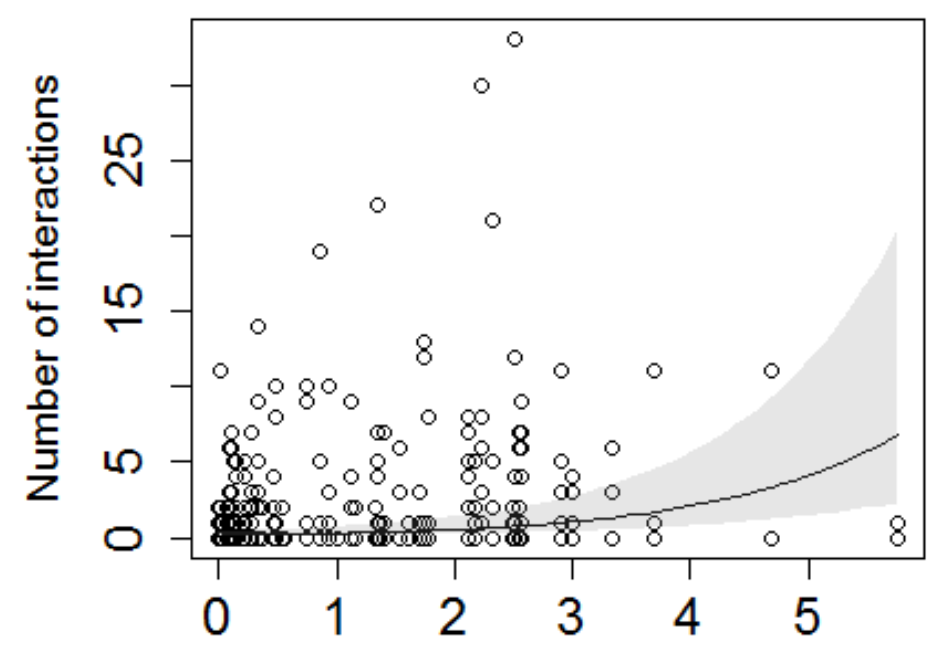

Relationship strength infant-receiver [CSIr] 
Fig 3: :

Effect in the final model of the strength of the infant-holder relationship (CSIh) and the infantreceiver relationship (CSIr) on the frequency of bridging interactions for a given initiator-infantreceiver combination.

The model selection results for the model testing prediction 2 are summarized in table S3 of the supplement. The rank distance between the holder and the involved male (receiver or bystander; $|\Delta \mathrm{DShm}|)$ and between receiver and bystander ( $\Delta \mathrm{DSrb})$ did not improve the null model. Adding the difference between the CSI of the infant-receiver and the infant-bystander dyad ( $\triangle$ CSIrb) improved the model (Table 2, Fig 4) and was retained as the only predictor in the final model. An increase of $\Delta$ CSIrb (ranging between -3.68 and 3.68) by 1.0 increased the probability that a male was selected $1.69-2.67$ times.

Table 2: Result of the final model for GLMM predicting the choice of a male as the receiver of a bridging interaction with a specific infant including the difference in social relationship between infant and receiver and the social relationship strength between infant and bystander ( $\Delta C$ SIrb) as predictors

\begin{tabular}{llllr}
$\mathrm{N}=112$ & Estimate & SE & \multicolumn{2}{l}{$95 \%$ confidence interval } \\
\hline Intercept & $-2.554 \mathrm{E}-10$ & $1.521 \mathrm{E}-01$ & -0.352 & 0.327 \\
$\Delta$ CSIrb & 0.744 & 0.116 & $\mathbf{0 . 5 2 7}$ & $\mathbf{0 . 9 8 3}$
\end{tabular}

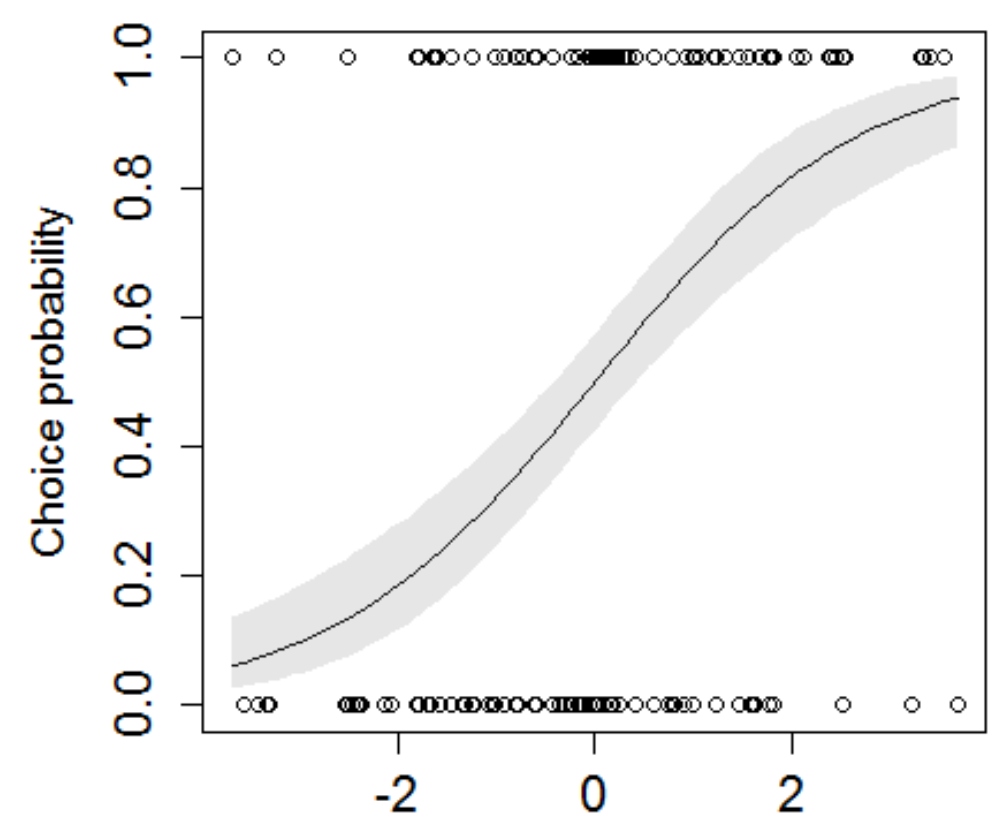


Fig 4: Effect of the relative strength of a male's relationship with the infant ( $\Delta$ CSIrb) on the probability that a male was chosen over a bystander as the partner for a male-infant-male bridging interaction.

\section{Discussion}

Our results support the hypothesis that males choose their partners based on the relative strength of the affiliative relationship the partner has with the infant. First, the number of bridging interactions of an initiator-infant-receiver triad was predicted by the strength of the relationship between the infant and the recipient of the interaction after controlling for the effect of the relationship between the infant and its holder. Second, an infant-holder's choice between two males in proximity of the interaction was predicted by the strength of their affiliative relationships with the infant. The stronger a male's relationship relative to the other male the more likely he was chosen as a receiver instead of being left as a bystander to the interaction. Neither relative nor absolute rank of the receiver was a significant predictor of the distribution of bridging interactions. These patterns in male bridging interactions indicate the use of triadic awareness. Males as initiators of the interactions use their knowledge of the relationships that other males have with an infant they are currently holding when choosing the receiver of the interaction..

The use of triadic awareness in the context of infant handling has been first suggested in Tibetan macaques (Ogawa 1995b). In most bridging interactions that were initiated by infant holders, the receiver was provided with the infant he handled the most often, his "affiliated infant". These results led to the conclusion that the male holding an infant choses a specific infant based on his knowledge of the preferences of potential receivers. Similarly, our results suggest that Barbary macaque males use knowledge of the relationships between infants and other males when they select partners for the bridging interactions. However, we based our study on a slightly different assumption and methodology than previous studies and provide new details that were previously unavailable.

We did not assume that holders chose specific infants based on the relationship that an available male (potential receiver) has with different infants (e.g. Ogawa 1995b for Tibetan macaques), but that the holder chooses specific male (receiver) based on the infant he has access to. This adjustment is based on the patterns of infant handling in Barbary macaques, in which bridging interactions are typically preceded by or alternating with long dyadic handling periods between infant and one of the males later involved in the bridging interaction (see Deag and Crook 1971). The low availability of infants leads to long handling episodes making it rather unlikely that males would be able to find a particular infant (or be motivated to "give up" one infant for another) based on their choice of a receiver male. We suggest that males rather keep one infant for a long time and search for a suitable receiver. This view is supported by our result that males were more likely to be chosen as receivers the stronger 
their relationship to the infant relative to the second available male. We cannot completely rule out, however, that both mechanisms - selection of particular infant and a particular receiving male depending on their relationship - act in concert. Future research should assess in more detail the availability of other potential receivers and other infants to quantify constraints on both mechanisms.

In our study we used a composite sociality index to measure the strength of infantmale relationships instead of using the frequency of interactions (Ogawa 1995b). Due to long periods of dyadic infant handling, it is likely, that males mainly reflect the duration of the interactions between other males and infants when assessing infant-male relationship strength. Thus, a composite index that combines frequency and duration of different behaviours might be better suited for the assessment of infant-male relationships in this species. Our CSI quantified how strong the relationship to one male was relative to the average relationship of the specific infant to all males. The distribution of CSI values shows that each infant realizes a number of relationships varying in strength rather than affiliating almost exclusively with a single male. Thus knowledge of third-party relationship may not be restricted to the ability to distinguish between two categories of individuals (affiliated vs. non-affiliated), but might reflect continuous variation in the strength of different relationships. It is a task for a future study to investigate the effect of the used method of relationships assessment on the results and explain in more details, how males evaluate the infant-male relationships (e.g. whether it is rather frequency or duration of interactions that they reflect and which interactions are the most important).

As mentioned in the introduction, some previous studies struggled to distinguish whether the individual used triadic awareness or acted based on an egocentric view of the world and the strength of his own relationships (see e.g. Perry et al. 2004). In order to reduce this problem, we controlled the holder's relationships with the infant and absolute and relative dominance rank of the receiver which may affect the holder's choice of the receiver according to previous studies (Deag and Crook 1971; Paul et al. 1996). We also suggest, that the study of triadic awareness of infant-male relationships might be less vulnerable to the described problem of ambiguity compared to the studies based on dominance relationships, where being part of the same hierarchy an individual may base its knowledge of others' dominance relationships either on monitoring of their interactions (triadic awareness) or on their own dominance relationships with each of other individuals, e.g. the individual who ranks in between two others may recruit the higher ranking from both opponents based on own relationships ( Range and Noë 2005; Bissonnette et al., 2009). Contrary to that, the relationship that other males have with the infant cannot be easily deduced from one's own relationships. Holders, whose awareness we assess, have a relationship with the infant they hold. The strength of this relationship influences how often the infant is available for other males, but does not affect how the time is distributed among them. Infant-male relationships also differ from relationships females establish amongst each other. In male dispersal species female relationships are strongly affected by maternal relatedness (Hamilton 1964; Ruiter and Geffen 1998; Silk et al. 2006) which allows to predict one female's behaviour from the behaviour of a relative to some degree. Unlike females in matrilinearly structured societies the more individualistic males can also be expected to be independent of each other in developing preferences for certain infants. Thus an understanding of a certain infant-male relationship needs to be based on the monitoring of interactions of the given dyad.

The main difference between infant-male and most other affiliative relationships is their ephemerality. Infant handling is very seasonal. Male interest in infants peaks shortly after birth and rapidly decreases (see Berghänel et al. 2011). As a consequence, relationships are transient and males have very little time to assess the quality of others' infant-male 
relationships and to implement this knowledge during bridging interactions. The fact that males establish triadic awareness of quickly emerging and quickly fading relationships indicates their ability to update their knowledge of others' relationships quite quickly.

Seasonality of infant handling also implies that males invest in monitoring third party relationship despite the fact that the information is quickly outdated and needs to be gathered again every year. In light of these investments it seems relevant to ask how males benefit from using knowledge about third party relationships during bridging and how these interactions are linked to dyadic infant handling. It has been suggested, that bridging interactions mainly serve to establish and maintain bonds among males. The agonistic buffering hypothesis (Deag and Crook 1971) proposes that holding an infant, males can approach even higher ranking males without being attacked and have a chance to improve and/or re-establish disturbed relationships and reduce stress. The relationship management hypothesis (Paul et al. 1996) emphasizes, that bridging gives males the opportunity to interact peacefully in general and not only after a conflict and that the interactions may contribute to male-male bonding, that is profitable in various ways (Kümmerli and Martin 2008) even long term, e.g. via coalition formation (Widdig et al. 2000; Young et al. 2014a). Being provided with his preferred infant the approached male could be more likely to establish an affiliative relationship with the holder, which may become beneficial in terms of coalitionary support as shown in the study species (Berghänel et al. 2011; Young et al. 2014a). The infant preferred by the receiver may be a more effective „,buffer“ against aggression because the approached male may tend to avoid a conflict that could harm his favourite infant. If males handle infants to regulate their relationship with the mother (e.g. Ménard et al. 2001; Smuts 1985), the receiver should also avoid aggression towards the holder plus infant because it could disturb his own relationships with the infant's mother (Ogawa 1995b).

The use of triadic awareness may be guided also by mechanisms including hormonal regulation and stress reduction. According to the Social buffering hypothesis (not to be confused with the Agonistic buffering hypothesis) any affiliative interaction with a closely bonded individual may decrease physiological stress response which consequently increases individual health (Strum 1984; Cohen and Wills 1985; Hennessy et al. 2009). The hormonal response to the social contact (social buffering) depends on the emotional state of the interacting individuals (Kikusui et al. 2006). Hence the strength of the relationship between the infant and the receiver may predict behavioural responses of the receiver and his hormonally regulated attitude towards the initiator that also feeds back on the hormonal response of the initiator. This suggests that choosing receiver based on the infant's relationships may drive a hormonally mediated positive loop (Nagasawa et al. 2015) that benefits both individuals. Future research will have to show how levels of physiological stress, aggression-related hormones and bonding-related hormones are linked (see e.g. Wingfield et al. 1990; Henkel et al. 2010; Young et al. 2014b).

\section{Conclusion}

Our results indicate that Barbary macaque males recognize affiliative relationships of infants and other males and make use of this triadic awareness when choosing male partners for bridging interactions. The capacity for monitoring, memorizing, and acting upon the social relationships of others has already been documented, but previous studies usually focused on different types of relationships and different contexts of usage. Here we provide evidence for the use of triadic awareness that is not related to aggression and is based on temporarily very dynamic affiliative infant-male relationships 
The use of complex social knowledge in various gregarious species (e.g. Engh et al. 2005) supports the view that the development of cognitive skills was enhanced by challenges of group living (Holekamp 2007; Byrne and Whiten 1989; Jolly 1966) and/or is associated with cooperative breeding (Burkart and van Schaik 2009; but see also Thornton and

McAuliffe 2015). The use of triadic awareness in infant handling may be of particular interest in this discussion due to its functional importance for social bonding as well as possible interrelation with cooperative care of infants.

\section{Acknowledgement:}

This study was supported by grant 009/2014/P, 159/2013/P and xx provided by the Grant Agency of the University of South Bohemia, Christian-Vögel Fond for Field Research of the German Society for Primatology and by the scholarship of the German Academic Exchange Service DAAD. We are grateful to the Haut Commissariat aux Eaux et Forets et a la Lutte Contre la Desertification of Morocco for research permission and professor Mohamed Mouna (Institute Scientifique de Rabat) and professor Mohamed Quarro (Ecole Nationale Forestiere d'Ing enieurs, Morocco) for their invaluable support and cooperation during the field work. We appreciate support and comments of all our collaborators and colleagues that contributed to the realization of the study and preparation of the manuscript. We particularly appreciate advices and support from James Waterman, Josephine Kalbitz, Andreas Berghänel, Christopher Young, Christina Haunhorst and Stanislav Lhota. Special thank goes also to Els van Lavieren, the director of the Moroccan Primate Conservation Foundation for her help and effort related with the protection of wild populations of Barbary macaques.

\section{Compliance with ethical standards}

\section{Conflict of interest}

The authors declare that they have no conflict of interest.

\section{Ethical approval:}

Our study was observational and non-invasive. All applicable international, national, and/or institutional guidelines for the care and use of animals were followed. All procedures performed in this study were in accordance with the IPS standards for the use of non-human primates in research. 


\section{Bibliography}

Altmann J (1974) Observational study of behavior: sampling methods. Behaviour 49:227-266

Bachmann C, Kummer H (1980) Male assessment of female choice in hamadryas baboons. Behav Ecol Sociobiol 6:315-321. doi: 10.1007/BF00292774

Bates D, Mächler M, Bolker B, Walker S (2015) Fitting linear mixed-effects models using Ime4. J Stat Softw. doi: 10.18637/jss.v067.i01

Berghänel A, Ostner J, Schröder U, Schülke O (2011) Social bonds predict future cooperation in male Barbary macaques, Macaca sylvanus. Anim Behav 81:1109-1116

Bergman TJ, Beehner JC, Cheney DL, Seyfarth RM (2003) Hierarchical classification by rank and kinship in baboons. Science 302:1234-1236

Bernstein IS, Cooper MA (1998) Ambiguities in the behavior of Assamese macaques. Am J Primatol 45:170-171

Bissonnette A, De Vries H, van Schaik CP (2009) Coalitions in male Barbary macaques, Macaca sylvanus: strength, success and rules of thumb. Anim Behav 78:329-335. doi: 10.1016/j.anbehav.2009.05.010

Bowerman BL, O'Connell RT (1990) Linear statistical models: An applied approach. PWS-Kent Publishing Company

Burkart JM, van Schaik CP (2009) Cognitive consequences of cooperative breeding in primates? Anim Cogn 13:1-19. doi: 10.1007/s10071-009-0263-7

Busse C, Hamilton WJ (1981) Infant carrying by male chacma baboons. Science 212:1281-1283. doi: 10.1126/science.212.4500.1281

Busse CD, Gordon TP (1984) Infant carrying by adult male mangabeys (Cercocebus atys). Am J Primatol 6:133-141

Call J, Aureli F, De Waal F (2002) Postconflict third-party affiliation in stumptailed macaques. Anim Behav 63:209-216

Chalmers NR (1968) The social behaviour of free living mangabeys in Uganda. Folia Primatol 8:263281

Cheney DL, Seyfarth RM (1980) Vocal recognition in free-ranging vervet monkeys. Anim Behav 28:362-367

Cheney DL, Seyfarth RM, Smuts B (1986) Social relationships and social cognition in nonhuman primates. Science 234:1361-1366

Cheney DL, Seyfarth RM (1989) Redirected aggression and reconciliation among vervet monkeys, Cercopithecus aethiops. Behaviour 110:258-275 
Cheney DL, Seyfarth RM, Silk JB (1995) The responses of female baboons (Papio cynocephalus ursinus) to anomalous social interactions: Evidence for causal reasoning? J Comp Psychol 109:134

Cheney DL, Seyfarth RM (1999) Recognition of other individuals' social relationships by female baboons. Anim Behav 58:67-75

Clutton-Brock TH (2006) Cooperative breeding in mammals. In: Cooperation in primates and humans. Springer, pp 173-190

Cohen S, Wills TA (1985) Stress, social support, and the buffering hypothesis. Psychol Bull 98:310

Collins DA (1986) Interactions between adult male and infant yellow baboons (Papio c. cynocephalus) in Tanzania. Anim Behav 34:430-443

Connor RC (2007) Dolphin social intelligence: complex alliance relationships in bottlenose dolphins and a consideration of selective environments for extreme brain size evolution in mammals. Philos Trans R Soc Lond B Biol Sci 362:587-602

Deag JM (1980) Interactions between males and unweaned Barbary macaques: Testing the agonistic buffering hypothesis. Behaviour 54-81

Deag JM, Crook JH (1971) Social behaviour and "agonistic buffering"in the wild barbary macaque Macaca sylvana L. Folia Primatol 15:183-200

De Vries H, Netto WJ, Hanegraaf PL (1993) Matman: a program for the analysis of sociometric matrices and behavioural transition matrices. Behaviour 125:157-175

De Waal FBM (2007) Chimpanzee politics: Power and sex among apes. JHU Press

De Waal FBM (1991) Complementary methods and convergent evidence in the study of primate social cognition 1). Behaviour 118:297-320. doi: 10.1163/156853991X00337

De Waal FBM (1986) The integration of dominance and social bonding in primates. Q Rev Biol 61:459-479

De Waal FBM, van Hooff JA, Netto WJ (1976) An ethological analysis of types of agonistic interaction in a captive group of Java-monkeys (Macaca fascicularis). Primates 17:257-290

Dunbar RIM (1984) Infant-use by male gelada in agonistic contexts: Agonistic buffering, progeny protection or soliciting support? Primates 25:28-35

Engh AL, Siebert ER, Greenberg DA, Holekamp KE (2005) Patterns of alliance formation and postconflict aggression indicate spotted hyaenas recognize third-party relationships. Anim Behav 69:209-217

Estrada A, Sandoval JM (1977) Social relations in a free-ranging troop of stumptail macaques (Macaca arctoides): Male-care behaviour I. Primates 18:793-813

Ferreira RG, Izar P, Lee PC (2006) Exchange, affiliation, and protective interventions in semifreeranging brown capuchin monkeys (Cebus apella). Am J Primatol 68:765-776. doi: 10.1002/ajp.20277 
Fooden J (2007) Systematic review of the Barbary macaque, Macaca sylvanus (Linnaeus, 1758). Fieldiana Zool 1-60

Hamilton, WD (1964) The genetical evolution of social behavior, I \& II. J Theor Biol 104:451-471

Hennessy MB, Kaiser S, Sachser N (2009) Social buffering of the stress response: diversity, mechanisms, and functions. Front Neuroendocrinol 30:470-482

Hinde RA (1976) Interactions, relationships and social structure. Man 1-17

Hrdy SB (1976) Care and exploitation of nonhuman primate infants by conspecifics other than the mother. Adv Study Behav 6:101-158

Hrdy SB (2007) Evolutionary context of human development: The cooperative breeding model. Fam Relatsh Evol Perspect 39-68

Johnson CM (2010) Observing cognitive complexity in primates and cetaceans. J Comp Psychol 23:587-624

Jolly A (1966) Lemur social behavior and primate intelligence. Science 153:501-506

Judge P (1982) Redirection of aggression based on kinship in a captive group of pigtail macaques. Int J Primatol 3:225-237

Judge PG (1991) Dyadic and triadic reconciliation in pigtail macaques (Macaca nemestrina). Am J Primatol 23:225-237

Kikusui T, Winslow JT, Mori Y (2006) Social buffering: relief from stress and anxiety. Philos Trans R Soc Lond B Biol Sci 361:2215-2228

Kitchen DM, Cheney DL, Seyfarth RM (2005) Male chacma baboons (Papio hamadryas ursinus) discriminate loud call contests between rivals of different relative ranks. Anim Cogn 8:1-6

Kuester J, Paul A, Arnemann J (1994) Kinship, familiarity and mating avoidance in Barbary macaques, Macaca sylvanus. Anim Behav 48:1183-1194

Kümmerli R, Martin RD (2008) Patterns of infant handling and relatedness in Barbary macaques (Macaca sylvanus) on Gibraltar. Primates 49:271-282

Lehmann J, Korstjens AH, Dunbar RIM (2007) Group size, grooming and social cohesion in primates. Anim Behav 74:1617-1629. doi: 10.1016/j.anbehav.2006.10.025

Ménard N, Scheffrahn W, Vallet D, Zidane C, Reber C (1992) Application of blood protein electrophoresis and DNA fingerprinting to the analysis of paternity and social characteristics of wild Barbary macaques. In: Martin RD, Dixson AF, Wickings EJ (eds) Paternity in primates: genetic tests and theories, Basel: Karger, pp 155-174

Ménard N, von Segesser F, Scheffrahn W, Pastorini J, Vallet D, Gaci B, Martin RD, Gautier-Hion A (2001) Is male-infant caretaking related to paternity and/or mating activities in wild Barbary macaques (Macaca sylvanus)? Comptes Rendus Académie Sci Sér III Sci Vie 324:601 
Moscovice LR, Di Fiore A, Crockford C, Kitchen DM, Wittig R, Seyfarth RM, Cheney DL (2010) Hedging their bets? Male and female chacma baboons form friendships based on likelihood of paternity. Anim Behav 79:1007-1015

Nagasawa M, Mitsui S, En S, Ohtani N, Ohta M, Sakuma Y, Onaka T, Mogi K, Kikusui T (2015) Oxytocin-gaze positive loop and the coevolution of human-dog bonds. Science 348:333-336. doi: 10.1126/science.1261022

Nguyen N, van Horn RC, Alberts SC, Altmann J (2009) "Friendships" between new mothers and adult males: adaptive benefits and determinants in wild baboons (Papio cynocephalus). Behav Ecol Sociobiol 63:1331-1344

Ogawa $\mathrm{H}$ (1995a) Bridging behavior and other affiliative interactions among male Tibetan macaques (Macaca thibetana). Int J Primatol 16:707-729

Ogawa $\mathrm{H}$ (1995b) Recognition of social relationships in bridging behavior among Tibetan macaques (Macaca thibetana). Am J Primatol 35:305-310

Ostner J, Vigilant L, Bhagavatula J, Franz M, Schülke O (2013) Stable heterosexual associations in a promiscuous primate. Anim Behav 86:623-631. doi: 10.1016/j.anbehav.2013.07.004

Paul A (1999) The socioecology of infant handling in primates: Is the current model convincing? Primates 40:33-46

Paul A, Kuester J, Arnemann J (1992) DNA fingerprinting reveals that infant care by male Barbary macaques (Macaca sylvanus) is not paternal investment. Folia Primatol 58:93-98

Paul A, Kuester J, Arnemann J (1996) The sociobiology of male-infant interactions in Barbary macaques, Macaca sylvanus. Anim Behav 51:155-170

Peake TM, Terry AMR, McGregor PK, Dabelsteen T (2002) Do great tits assess rivals by combining direct experience with information gathered by eavesdropping? Proc R Soc Lond B Biol Sci 269:1925-1929

Perry S, Barrett HC, Manson JH (2004) White-faced capuchin monkeys show triadic awareness in their choice of allies. Anim Behav 67:165-170

Quinn GP, Keough MJ (2002) Experimental design and data analysis for biologists. Cambridge University Press

R Core Team (2014) R: A language and environment for statistical computing. R Foundation for Statistical Computing, Vienna, Austria. 2013.

Range F, Noë R (2005) Can simple rules account for the pattern of triadic interactions in juvenile and adult female sooty mangabeys? Anim Behav 69:445-452

Riedman ML (1982) The evolution of alloparental care and adoption in mammals and birds. Q Rev Biol 57:405-435

Ruiter JD, Geffen E (1998) Relatedness of matrilines, dispersing males and social groups in long-tailed macaques (Macaca fascicularis). Proc R Soc Lond B Biol Sci 265:79-87 
Schino G, Tiddi B, Di Sorrentino EP (2006) Simultaneous classification by rank and kinship in Japanese macaques. Anim Behav 71:1069-1074

Schino G, Tiddi B, Di Sorrentino EP (2007) Agonistic support in juvenile Japanese macaques: cognitive and functional implications. Ethology 113:1151-1157

Schmid VS, De Vries H (2013) Finding a dominance order most consistent with a linear hierarchy: an improved algorithm for the I\&SI method. Anim Behav 86:1097-1105

Schülke O, Bhagavatula J, Vigilant L, Ostner J (2010) Social bonds enhance reproductive success in male macaques. Curr Biol 20:2207-2210. doi: 10.1016/j.cub.2010.10.058

Schwarz G(1978) Estimating the dimension of a model. Ann Stat 6:461-464

Seed AM, Clayton NS, Emery NJ (2007) Postconflict third-party affiliation in rooks, Corvus frugilegus. Curr Biol 17:152-158. doi: 10.1016/j.cub.2006.11.025

Silk JB (1999) Male bonnet macaques use information about third-party rank relationships to recruit allies. Anim Behav 58:45-51

Silk JB (2007a) Social components of fitness in primate groups. Science 317:1347-1351

Silk JB (2007b) The adaptive value of sociality in mammalian groups. Philos Trans R Soc Lond B Biol Sci 362:539-559

Silk JB, Samuels A (1984) Triadic interactions among Macaca radiata: Passports and buffers. Am J Primatol 6:373-376

Silk JB, Alberts SC, Altmann J (2003) Social bonds of female baboons enhance infant survival. Science 302:1231-1234

Silk JB, Altmann J, Alberts SC (2006) Social relationships among adult female baboons (Papio cynocephalus) I. Variation in the strength of social bonds. Behav Ecol Sociobiol 61:183-195

Silk JB, Beehner JC, Bergman TJ, Crockford C, Engh AL, Moscovice LR, Wittig RM, Seyfarth RM, Cheney DL (2009) The benefits of social capital: close social bonds among female baboons enhance offspring survival. Proceedings of the Royal Society B: Biological Sciences 276:3099-3104

Small MF (1990) Promiscuity in Barbary macaques (Macaca sylvanus). Am J Primatol 20:267-282

Smuts BB (1985) Sex and friendship in baboons. Aldine, New York

Smuts BB, Gubernick DJ (2015) Male-infant relationships in nonhuman primates: Paternal investment or mating effort. Father-Child Relat Cult Biosoc Contexts 1-30

Stein DM (1984) The sociobiology of infant and adult male baboons. Norwood, Ablex Publishing Corporation

Sterck EHM, Watts DP, van Schaik CP (1997) The evolution of female social relationships in nonhuman primates. Behav Ecol Sociobiol 41:291-309

Strum SC (1984) Why males use infants. In Taub DM (ed) Primate Paternalism, Van Nostrand Reinhold, New York, pp 146-185 
Taub DM (1980) Testing the "agonistic buffering"hypothesis. Behav Ecol Sociobiol 6:187-197

Taub DM (1984) Male caretaking behavior among wild Barbary macaques (Macaca sylvanus). In Taub DM (ed) Primate Paternalism, Van Nostrand Reinhold, New York, pp 20-55

Thierry B, Bynum E, Baker S, Kinnaird MF, Matsumura S, Muroyama Y, O'Brien TG, Petit O, Watanabe K (2000) The social repertoire of Sulawesi macaques. Primate Res 16:203-226

Thornton A, McAuliffe K (2015) Cognitive consequences of cooperative breeding? A critical appraisal. Journal of Zoology 295:12-22

Tomasello M, Call J (1997) Primate cognition. Oxford University Press, Oxford

van Hooff JARAM, van Schaik CP (1994) Male bonds: afilliative relationships among nonhuman primate males. Behaviour 130:309-337. doi: 10.1163/156853994X00587

van Schaik CP, Paul A (1996) Male care in primates: does it ever reflect paternity? Evol Anthropol Issues News Rev 5:152-156

Whitten PL (1987) Infants and adult males. In: Smuts BB, Cheney DL, Syfarth RM, Wrangham RW, Struhsaker TT (eds) Primate societies, University of Chicago Press, Chicago, pp 343-357

Widdig A, Streich WJ, Tembrock G (2000) Coalition formation among male Barbary macaques (Macaca sylvanus). Am J Primatol 50:37-51

Woodroffe R, Vincent A (1994) Mother's little helpers: Patterns of male care in mammals. Trends Ecol Evol 9:294-297. doi: 10.1016/0169-5347(94)90033-7

Young C, Majolo B, Schülke O, Ostner J (2014) Male social bonds and rank predict supporter selection in cooperative aggression in wild Barbary macaques. Anim Behav 95:23-32

Young C, Majolo B, Heistermann M, Schülke O, Ostner J (2014) Responses to social and environmental stress are attenuated by strong male bonds in wild macaques. Proceedings of the National Academy of Sciences 111:18195-18200

Zhao Q-K (1996) Male-infant-male interactions in Tibetan macaques. Primates 37:135-143. doi: 10.1007/BF02381401

\section{Supplement}

Table S1: Distribution of 654 analyzed bridging interactions: Representation of bridging interactions of different dyads, proportion from all possible combinations, variability in numbers of interactions for those dyads that performed the behavior.

\begin{tabular}{|l|l|l|l|l|}
\hline $\mathrm{N}=654$ & Number $(\%)$ & $\max$ & mean & sd \\
\hline Infant-holder & $52(74 \%)$ & 81 & 12.58 & 15.95 \\
\hline
\end{tabular}




\begin{tabular}{|l|l|l|l|l|}
\hline Infant-receiver & $57(81 \%)$ & 51 & 11.47 & 10.99 \\
\hline Holder-receiver & $41(97 \%)$ & 59 & 15.95 & 13.40 \\
\hline Male-male & $21(100 \%)$ & 72 & 31.14 & 18.01 \\
\hline
\end{tabular}

Table S2: Distribution of 112 analyzed bridging interactions with bystanders: Representation of bridging interactions of different dyads, proportion from all possible combinations, variability in numbers of interactions for those dyads that performed the behavior.

\begin{tabular}{|l|l|r|r|r|}
\hline $\mathrm{N}=112$ & Number $(\%)$ & Max & mean & \multicolumn{1}{l|}{ sd } \\
\hline Infant-holder & $22(52 \%)$ & 20 & 5.18 & 4.75 \\
\hline Infant-receiver & $29(69 \%)$ & 14 & 3.80 & 3.39 \\
\hline Infant-bystander & $34(81 \%)$ & 9 & 3.13 & 2.21 \\
\hline Holder-bystander & $37(88 \%)$ & 7 & 2.85 & 2.08 \\
\hline Holder-receiver & $32(76 \%)$ & 13 & 3.56 & 3.32 \\
\hline Receiver-bystander & $39(93 \%)$ & 6 & 2.78 & 1.75 \\
\hline
\end{tabular}

Fig S1: Distribution of the strength of the relationship (measured as composite sociality index, CSI) between infant-male dyads.

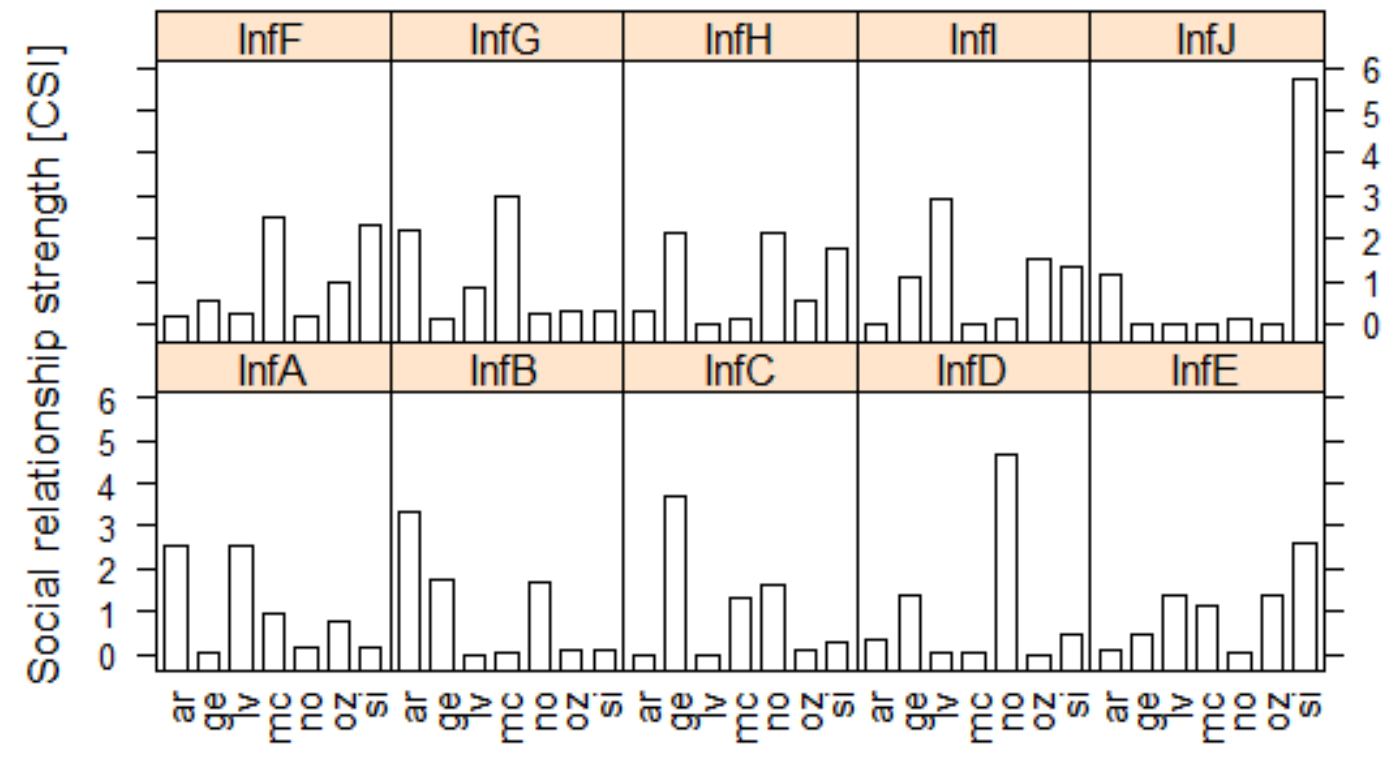

Male 
Table S3: Results of the predictor selection for GLMM (testing H1): Change of BIC when adding predictors into null model and model including already chosen predictors (CSIr and CSIh).

Significances from likelihood-ratio tests are also presented.

\begin{tabular}{lllll} 
& null & \multicolumn{3}{c}{ CSIr+CSIh } \\
& BIC & $\mathrm{p}$ & BIC & $\mathrm{p}$ \\
\hline & 1250.2 & & 1076.9 \\
\hline Season & 1254.8 & 0.222 & 1082.7 & 0.655 \\
DSr & 1255.5 & 0.376 & 1082.7 & 0.643 \\
$\mid \Delta$ DShr $\mid$ & 1255.6 & 0.426 & 1082.6 & 0.567 \\
CSIh & 1149.3 & $<2 \mathrm{e}-16^{* * *}$ & $\mathrm{x}$ & $\mathrm{x}$ \\
CSIr & 1232.8 & $8.30 \mathrm{e}-07^{* * *}$ & $\mathrm{x}$ & $\mathrm{x}$
\end{tabular}

Table S4. Results of the predictor selection for GLMM (testing H2): Change of BIC when adding predictors into null model and model including already chosen predictors (CSIr and CSIh).

Significances from likelihood-ratio tests are also presented.

\begin{tabular}{lllll} 
& null & & CSIbr \\
& BIC & $p$ & BIC & $p$ \\
\hline & 331.1 & & 281.7 & \\
\hline $\mid \Delta$ DShm| & 336.3 & 0.660 & 286.9 & 0.712 \\
$\Delta$ DSrb & 333.0 & 0.063 & 287.1 & 0.944 \\
$\Delta$ CSIrb & 281.7 & $1.304 \mathrm{e}-13^{* * *}$ & $\mathrm{x}$ & $\mathrm{x}$
\end{tabular}

